\title{
EFETIVIDADE DO ACESSO ELETRÔNICO À JUSTIÇA DIRETAMENTE PELO CIDADÃO EM TEMPOS DE PANDEMIA: ATERMAÇÃO ONLINE
}

\section{ELECTRONIC ACCESSES' EFFECTIVENESS DIRECTLY BY THE CITIZENS ON PANDEMIC TIMES: ON-LINE ATHERMATION}

\section{Leila Maria Tinoco Boechat Ribeiro Carlos Henrique Medeiros de Souza*}

Resumo: $\mathrm{O}$ acesso à Justiça pela via eletrônica, mormente em meio à pandemia do Coronavírus, em que os órgãos jurisdicionais se encontram com suas atividades presenciais suspensas, torna-se ainda mais desafiador àqueles cidadãos que ainda não dispõem de meios tecnológicos e/ou o conhecimento técnico para sua utilização. Nesse contexto, em que os tribunais implementam a atermação online como uma das alternativas para facilitação de acesso à Justiça, por parte do cidadão, apresenta-se a seguinte questão problema: De que maneira a atermação online tem contribuído para a efetividade do direito de acesso à Justiça, diretamente pelo cidadão, nesse momento de excepcionalidade da COVID-19? Objetiva-se analisar a atermação online como meio de assegurar efetividade ao direito humano/fundamental de acesso à Justiça ao cidadão, de forma direta, pela via eletrônica, no contexto da COVID-19, numa abordagem interdisciplinar Direito e Novas Tecnologias da Informação e Comunicação, perpassando fundamentos teóricos sobre a temática e trazendo-se à baila entrevista com pessoa idosa, 65 anos, sexo feminino, sobre sua experiência no ajuizamento de ação, via atermação online, para obtenção de benefício assistencial. Justifica-se o estudo por sua relevância acadêmica e social à medida que visa a contribuir para a efetividade do direito humano de acesso à Justiça do cidadão. A metodologia adotada é qualitativa, quanto ao problema; exploratória, quanto aos objetivos; e pesquisa bibliográfica e entrevista, quanto aos procedimentos técnicos. Espera-se favorecer a efetividade do direito de acesso à Justiça do cidadão, pela via eletrônica, nos amplos termos em que consagrado no ordenamento pátrio e diplomas internacionais.

Palavras-chave: Acesso. Justiça. Cidadão. Via eletrônica. Coronavírus.

Abstract: Access to justice by electronic means, especially in the midst of the Coronavirus pandemic, in which jurisdictional entities are suspended from their faceto-face activities, becomes even more challenging to those citizens who do not yet have technological means and / or knowledge of technical assistance for its use. In this context, in which the courts implement online tapping as one of the alternatives for facilitating access to Justice by the citizen, the following problem arises: How online

\footnotetext{
*Professora de Direitos Humanos e Especialista em Direito Público (UNIG - Campus V - Itaperuna/RJ). Oficiala de Justiça Avaliadora Federal (JFRJ). Mestre e Doutoranda do Programa de Pós-graduação Stricto Sensu em Cognição e Linguagem da Universidade Estadual do Norte Fluminense Darcy Ribeiro (UENF). E-mail: leilaboechat@yahoo.com.br

** Professor Associado e Coordenador do Programa de Pós-graduação Stricto Sensu em Cognição e Linguagem da Universidade Estadual do Norte Fluminense Darcy Ribeiro (UENF). Doutor em Comunicação pela Universidade Federal do Rio de Janeiro (UFRJ). E-mail: chmsouza@gmail.com
} 
tapping has contributed to the effectiveness of the right of access to Justice, directly by the citizen, in this moment of COVID-19 exceptionality? The objective is to analyze online banking as a means of ensuring effectiveness to the human / fundamental right of access to Justice for citizens, directly, electronically, in the context of COVID-19, in an interdisciplinary approach of Law and New Information and Communication Technologies, going through theoretical foundations on the subject and bringing up an interview with elderly person, 65 years old, female, about her experience in filing an action, via online banking, to obtain the social assistance benefit. The study is justified by its academic and social relevance as it aims to contribute to the effectiveness of the human right of access to citizens' Justice. The adopted methodology is qualitative, regarding the problem; exploratory, as to the objectives; and bibliographic research and interview, regarding technical procedures. It is expected to favor the effectiveness of the citizen's right to access Justice, by electronic means, in the broad terms in which it is enshrined in the national order and international diplomas.

Keywords: Access. Justice. Citizen. Electronic. Coronavirus. 


\section{INTRODUÇÃO}

As tecnologias da informação e comunicação, sobretudo após o advento da internet, têm sido cada vez mais utilizadas no âmbito do Judiciário nacional e contribuído para a modernização e aperfeiçoamento dos serviços judiciais, mais recentemente, mediante a implementação dos sistemas de processamento eletrônico.

Essa realidade do acesso à Justiça, pela via eletrônica, mormente em meio à pandemia do Coronavírus, em que os conflitos se intensificam e os órgãos jurisdicionais encontram-se com suas atividades presenciais suspensas, torna-se ainda mais desafiadora àqueles cidadãos que, embora possuam direito de acesso direto à Justiça, independentemente de advogado, nas hipóteses estabelecidas no ordenamento pátrio, ainda não dispõem de meios tecnológicos (computadores, smartphones, acesso à internet) e/ou o conhecimento técnico para sua utilização, sendo possível que não Ihes seja, na prática, assegurado esse direito garantia humano, nos amplos termos em que consagrado na Constituição e legislações pátrias.

Nesse contexto, os tribunais implementam, dentre as alternativas para facilitação desse acesso à Justiça, por parte do cidadão, a atermação online, que é a apresentação do seu pedido à Justiça, de forma direta, só que não de forma oral como prevista na Lei dos Juizados Especiais, mas pela via eletrônica. Apresenta-se assim a seguinte questão problema: De que maneira a atermação online tem contribuído para a efetividade do direito de acesso à Justiça, diretamente pelo cidadão, nesse momento de excepcionalidade vivenciada pela COVID-19?

Objetiva-se, nessa pesquisa, analisar a atermação online como meio de assegurar efetividade ao direito humano de acesso à Justiça, de forma direta, pela via eletrônica, no contexto da COVID-19, numa abordagem interdisciplinar do Direito e Novas Tecnologias da Informação e Comunicação, baseada na obra de autores como Cappelletti e Garth (1988), Souza (2003) e Barcellos (2018), perpassando fundamentos teóricos sobre o conceito de acesso à Justiça, processo eletrônico, trazendo-se à baila enriquecedora entrevista com Analicia de Fátima Ribeiro Freitas, 65 anos, sobre sua experiência de realização de ajuizamento de ação, via atermação online, para obtenção de benefício assistencial perante o Juizado Especial Federal Cível e Previdenciário de Itaperuna, Subseção Judiciária do Estado do Rio de Janeiro. 
Justifica-se o presente estudo por sua relevância acadêmica e social à medida que visa a contribuir para a efetividade do direito humano de acesso à Justiça do cidadão, sem cuja garantia se inviabiliza a proteção de quaisquer outros direitos.

A metodologia adotada é, portanto, qualitativa, quanto ao problema; exploratória, quanto aos objetivos; e pesquisa bibliográfica e entrevista, quanto aos procedimentos técnicos. Espera-se, em última análise, contribuir para a efetividade do direito de acesso à Justiça do cidadão brasileiro, pela via eletrônica, de forma direta e gratuita, como consagrado no ordenamento pátrio e nos diplomas internacionais.

\section{O ACESSO À JUSTIÇA COMO DIREITO HUMANO SOCIAL DO CIDADÃO}

Os direitos humanos, segundo Ramos (2020, p.31), "consistem em um conjunto de direitos considerado indispensável para a vida humana pautada na liberdade, igualdade e dignidade". Sua consagração, no plano internacional, teve como marco a Declaração Universal dos Direitos Humanos, proclamada em 10 de dezembro de 1948, que estabelece, dentre outros, o direito de acesso à Justiça, em seu artigo $X$ : "toda pessoa tem direito, em plena igualdade, a uma audiência justa e pública por parte de um tribunal independente e imparcial, para decidir de seus direitos e deveres ou do fundamento de qualquer acusação criminal contra ele" (ONU, 2009, p.7). A partir daí, esse direito essencial da pessoa humana passou a ser consagrado em pactos internacionais, como, no artigo 14.1 do Pacto Internacional de Direitos Civis e Políticos (BRASIL, 1992a) e no artigo 8oㅗ 1a Convenção Americana sobre Direitos Humanos - Pacto de São José da Costa Rica (BRASIL, 1992b).

No Brasil, o acesso à Justiça foi expressamente consagrado como direito fundamental pela Constituição de 1946, ao estabelecer que a lei não poderia excluir do Poder Judiciário qualquer lesão de direito individual (SEIXAS; SOUZA, 2013). Atualmente, esse direito é previsto, de forma mais ampla, pela Constituição da República Federativa do Brasil de 1988, no rol de direitos fundamentais do artigo 5ㅇ, em seu inciso XXXV: "a lei não excluirá da apreciação do Poder Judiciário lesão ou ameaça a direito" (BRASIL, [2020]). Tal dispositivo enuncia, pois, o direito humano e constitucional fundamental de acesso à Justiça que, segundo Cappelletti e Garth (1998), em sua obra intitulada "Acesso à Justiça", é expressão de difícil definição mas determina como finalidades básicas do sistema jurídico - aquele pelo qual se pode 
reivindicar direitos e/ou resolver litígios pelo Estado - a acessibilidade a todos e a produção de resultados individual e socialmente justos. Os mencionados autores debruçam-se, em sua obra clássica, sobre o primeiro aspecto, sem descuidar-se do segundo, afirmando ser o acesso efetivo um pressuposto da justiça social.

Trata-se de um direito social, de segunda geração ou dimensão que, opostamente aos direitos individuais ou de liberdade, impõe um fazer estatal para assegurar sua efetividade. E ainda, de um direito-garantia, segundo Barcellos (2018), por ser um direito em si, mas objetivar assegurar o respeito aos direitos e liberdades. Não bastasse, o pleno acesso à Justiça, como direito fundamental social que é, e nessa qualidade, corolário do princípio da igualdade, torna-se imprescindível para a eficácia jurídica da dignidade da pessoa humana. Isso porque, no entendimento de Barcellos (2008), o acesso à Justiça constitui, ao lado dos elementos materiais (educação, saúde e assistência aos desamparados), elemento instrumental do núcleo essencial ou mínimo existencial da dignidade humana, pois todas as pessoas devem ter acesso ao Judiciário e " [...] o acesso à Justiça é um meio, um instrumento para os demais direitos, mas não há um outro meio que viabilize o próprio acesso à Justiça" (BARCELLOS, 2008, p. 325).

\section{O ACESSO À JUSTIÇA PELA VIA ELETRÔNICA E OS DESAFIOS AOS DESCONECTADOS}

As novas tecnologias da informação e comunicação (NTICs) que, segundo Marinho (2017), são tecnologias e métodos para se comunicar surgidas no contexto da Revolução Informacional, Revolução Telemática ou Terceira Revolução Industrial, desenvolvidas gradativamente desde a segunda década de 1970, principalmente nos anos 1990, trazem consigo inúmeras vantagens, dentre as quais, podem-se destacar a maior facilidade e rapidez de acesso às informações e a melhor coordenação de colaboradores dispersos geograficamente. Por esse motivo, são caras aos ideais de modernização e celeridade processual buscados pelo Judiciário pátrio.

Assim, essas tecnologias, que não prescindem da internet para sua utilização (SOUZA, 2003), têm-se manifestado no contexto dos serviços judiciários não apenas sob forma de e-mails, sites, audiências por videoconferências, mas também, mais modernamente, sob a forma de sistemas eletrônicos de processamento e comunicações processuais via e-mail e WhatsApp. 
Embora crescente o número de brasileiros que acessam a internet, constatase que essa ainda não é a realidade de toda a população. A Pesquisa TIC Domicílios 2019, mais importante levantamento sobre acesso às tecnologias da informação e comunicação, realizada pelo Centro Regional para o Desenvolvimento de Estudos sobre a Sociedade da Informação (CETIC.br), vinculado ao Comitê Gestor da Internet no Brasil, realizada em 23.490 domicílios em todo o território nacional entre outubro de 2019 e março de 2020, constatou que o Brasil conta com 134 milhões de usuários de internet, o que representa $74 \%$ da população com 10 anos ou mais. Apesar do aumento significativo nos últimos anos na proporção da população brasileira que usa a Internet, cerca de um quarto dos indivíduos (47 milhões de pessoas) seguem desconectados, persistindo diferenças de acesso por renda, gênero, raça e regiões (CENTRO REGIONAL DE ESTUDOS PARA O DESENVOLVIMENTO DA SOCIEDADE DA INFORMAÇÃO, 2020).

Segundo Salvador (2020), os custos de acesso à internet no Brasil são bastante elevados, somando-se a isso os problemas de acesso à rede e, em alguns casos, a inexistência de acesso em algumas regiões devido à infraestrutura de telecomunicações, ocupando o Brasil a $111^{\text {a }}$ posição no mundo em qualidade e velocidade de internet, atrás de países como Quênia, Armênia e Marrocos.

Nesse contexto, o curso das conquistas processuais relativas ao acesso à Justiça poderia caracterizar um "vaivém das ondas cappellettianas", segundo estudos de Ribeiro, Frias e Souza (2018). Isso porque as conquistas no acesso à Justiça trazidas pelas três ondas renovatórias de Cappelletti e Garth (1988) - a assistência judiciária aos pobres, a representação dos interesses difusos e um novo enfoque de acesso à Justiça, traduzido pela Lei dos Juizados Especiais, acessível indistintamente a todos, informal e célere - parecem experimentar indevido retrocesso social em se considerando a forma exclusiva de acesso pela via eletrônica e o perfil da população brasileira, concernente ao acesso às tecnologias, resultado da Pesquisa TIC Domicílios 2019.

Evidente que o acesso do cidadão à Justiça, ainda que sob o enfoque do sistema acessível a todos (acesso institucionalizado à Justiça), não se restringe ao peticionamento pelo próprio cidadão, como é possível, por exemplo, em sede de Juizados Especiais e na Justiça trabalhista, as abrange sua efetiva participação no curso do processo. Inclui ainda o exercício, perante a Justiça, do direito de defesa 
que, nesse contexto do processo eletrônico, por sua vez, também demandará a observância das mesmas exigências de natureza tecnológica, podendo comprometer a efetividade de princípios constitucionais como o contraditório e a ampla defesa (RIBEIRO; SOUZA, 2019).

Assim, no âmbito das relações jurídico-processuais que, atualmente, no contexto da pandemia, mais que nunca, estabelecem-se e se desenvolvem em ambiente eletrônico, não prescindindo, portanto, do acesso às NTICs, persiste a barreira tecnológica de acesso à Justiça àqueles desconectados, cuja remoção ou considerável atenuação pode e deve se dar mediante a adoção de medidas, no âmbito do Judiciário nacional. Dentre essas medidas, encontram-se aquelas responsáveis por dar efetividade às normas já previstas na legislação pátria, apontadas por Ribeiro e Souza (2018): a manutenção de equipamentos de digitalização e de acesso à rede mundial de computadores à disposição dos interessados para distribuição de peças processuais, pelos órgãos jurisdicionais, à luz do artigo 10, § 3ํㅡㄹ da Lei do Processo Eletrônico (BRASIL, 2006), e a promoção da inclusão digital, a partir do fomento à cultura digital e promoção da internet como ferramenta social, conforme preconiza o artigo 27, inciso I, do Marco Civil da Internet (BRASIL, [2018]).

Na seção seguinte, traz-se à baila experiência bem-sucedida de acesso à Justiça, de forma direta por uma cidadã, pela via eletrônica, buscando-se exemplificar a efetividade a esse direito humano no excepcional contexto da pandemia do novo coronoavírus (COVID-19), sob o enfoque de acesso institucionalizado à Justiça, cuja efetividade é pressuposto lógico necessário do acesso à Justiça como valor do justo.

\section{A EFETIVIDADE DO ACESSO DIRETO À JUSTIÇA PELO CIDADÃO VIA ATERMAÇÃO ONLINE EM TEMPOS DE PANDEMIA}

Os Juizados Especiais Cíveis e Criminais e os Juizados Especiais Federais podem ser considerados locus característico do acesso direto do cidadão à Justiça, pois prescindem, para tanto, da presença de advogado, sendo atribuída, em seu âmbito, ao próprio cidadão a capacidade postulatória (ius postulandi). Informam-se tais órgãos jurisdicionais pelos critérios da oralidade, simplicidade, informalidade, economia processual e celeridade, nos termos do artigo $2^{\circ}$ da Lei ํo 9.099/95 - Lei dos Juizados Especiais Cíveis e Criminais (BRASIL, 1995) - lei geral aplicável à Lei 
no 10.259/01 - que institui os Juizados Especiais no âmbito da Justiça Federal relativamente às normas que com esta não conflitar.

Essas leis, que caracterizam a terceira onda cappellettiana, estabelecem a ampla acessibilidade do cidadão à Justiça pois, além de viabilizarem o acesso direto e gratuito, em prestígio aos mencionados critérios da oralidade, simplicidade e informalidade, no artigo 14 da Lei no 9.099/95, possibilitam ao cidadão instaurar seu processo mediante apresentação de pedido escrito ou oral à Secretaria do Juizado, fazendo dele constar em linguagem simples e acessível os dados que interessam à proteção do seu direito (nome, a qualificação e o endereço das partes; os fatos e os fundamentos, de forma sucinta; o objeto e seu valor), e, em sendo oral o pedido, estabelecendo que será reduzido a escrito ou a termo pela Secretaria do Juizado, ou seja, será realizada a atermação ou primeiro atendimento dos Juizados.

Ocorre que, com o advento da COVID-19, fora adotada como medida preventiva à disseminação da pandemia, por força da Resolução no 313, de 19 de março de 2020, do Conselho Nacional de Justiça (CNJ) (CONSELHO NACIONAL DE JUSTIÇA, 2020b), a suspensão das atividades presenciais do Judiciário nacional, mediante a implementação do trabalho remoto de magistrados e servidores e a realização de atos presenciais em hipóteses excepcionais, restritas à adoção de medidas de caráter urgente em regime de plantão judiciário.

Assim sendo, as dificuldades de acesso de alguns cidadãos à Justiça, pela via eletrônica, pelo já implementado processamento eletrônico - por eventualmente não disporem de meios tecnológicos e/ou o conhecimento técnico para sua utilização que Ihe permita por si o acesso à Justiça - potencializaram-se porque, nesse momento, diante do fechamento dos prédios do Judiciário, não Ihes seria possível exercer o direito de peticionamento escrito ou oral na Secretaria do Juizado tal como configurado no artigo 14 da Lei no 9099/95. Desse modo, visando a facilitar o acesso direto à Justiça por parte dos cidadãos, a Resolução no 317, de 30 de abril de 2020, do CNJ (CONSELHO NACIONAL DE JUSTIÇA, 2020a), em seu artigo 3으, estabeleceu que os tribunais deveriam instituir serviço de atermação online para dar resolutividade aos processos judiciais por benefícios previdenciários ou assistenciais.

Assim o fez a Justiça Federal do Rio de Janeiro, disponibilizando em seu site (https://www.jfrj.jus.br/) - que apresenta por mensagem inicial em destaque "A Justiça Federal não parou! Estamos trabalhando remotamente. Como ser atendido durante a 
pandemia?" - o serviço de primeiro atendimento online, fornecendo orientações específicas quanto a esse Primeiro Atendimento dos Juizados Especiais Federais. O site fornece ainda o link de ajuda no acesso aos sistemas processuais, listas de contato com as Varas, Juizados e Gabinetes, via e-mail, telefone ou WhatsApp, além de orientações gerais sobre o acesso à Justiça pelo cidadão no período da pandemia e fornecimento de telefones da central de teleatendimento, inclusive para informações sobre o processo eletrônico, e também das Seções de Atendimento ao Jurisdicionado e Cidadania. (SEÇÃO JUDICIÁRIA DO RIO DE JANEIRO, 2020a).

Utilizando-se então desse serviço de atermação ou primeiro atendimento online instituído pela Justiça Federal do Rio de Janeiro, a Sra. Analicia de Fátima Ribeiro Freitas (AFRF), 65 anos, brasileira, casada, do lar, residente na Usina Santa Isabel, distrito de Bom Jesus do Itabapoana-RJ, ajuizou AÇÃO PARA CONCESSÃO DO BENEFÍCIO ASSISTENCIAL BPC - LOAS em face do INSS - INSTITUTO NACIONAL DO SEGURO SOCIAL, em 08/07/2020, durante a pandemia do Coronavírus (COVID19), e compartilha nesse espaço sua experiência, mediante entrevista realizada por videochamada via WhatsApp, de que participam seu filho Geanderson Ribeiro Freitas (GRF), 34 anos, e sua nora Ingrid dos Santos Caetano Ribeiro Freitas (ISCRF), 23 anos - todos, inclusive a autora, com formação educacional até o ensino médio -, que não apenas a auxiliaram na propositura da ação por meio eletrônico, como também, na entrevista, complementando as informações relativas ao ajuizamento eletrônico realizado via Primeiro atendimento online pelo site da Seção Judiciária do Rio de Janeiro. As respostas dos entrevistados, a seguir transcritas, encontram-se adaptadas às normas da linguagem culta.

Pergunta 1 - A sra. propôs, durante a pandemia, perante a Justiça Federal ação pleiteando o benefício assistencial previsto na Lei Orgânica de Assistência Social? Por que motivo?

AFRF - Sim. Porque houve a negativa do benefício pelo INSS no pedido administrativo.

Pergunta 2 - Como a sra. soube que faria jus a esse benefício?

AFRF - Por minha sobrinha, que trabalha como atendente na Previdência Social (INSS), e me falou que eu tinha esse direito. Então, primeiro eu fiz o procedimento administrativo em abril de 2020, que também foi pela internet. 
Pergunta 3 - A pandemia de alguma forma agravou a sua situação financeira e de sua família?

AFRF - Agravou sim porque, por sermos idosos, do grupo de risco, eu e meu esposo, não pude sair para resolver as coisas. Meu filho, que morava em Cabo Frio e trabalhava lá como motorista de uber, teve que vir com a família morar com a gente para ajudar a cuidar de nós, principalmente do pai, pois ele teve AVC e é totalmente dependente de nós. Então hoje somos eu, meu esposo, meu filho, a nora e os três netos morando juntos aqui e as despesas são maiores porque eu não posso trabalhar e eles estão desempregados. Estamos contando com o auxílio emergencial que temos recebido e que tem ajudado nas despesas, mas não sabemos como será quando ele acabar.

Pergunta 4 - A sra. ajuizou essa ação através de advogado? Por quê?

AFRF - Não. Porque não tinha como pagar o advogado.

GRF - Não é fácil conseguir advogado que concorde em receber, ao final, se a pessoa vencer a ação. Além disso, nós conseguimos fazer pela internet, sem custo, o que o advogado iria fazer.

Pergunta 5 - Como a sra. soube que poderia ajuizar essa ação por si, sem advogado? AFRF - Minha sobrinha também disse que poderia fazer sem advogado, informou o site para o acesso e orientou como devia ser feito. Ela não é formada em Direito, mas ela também se informa com a mãe que trabalha no Fórum.

Pergunta 6 - A sra. ajuizou essa ação presencialmente ou eletronicamente? Por quê? De que forma? Por computador, notebook ou smartphone?

AFRF - De forma eletrônica, porque a Justiça não estava funcionando presencialmente. Usei meu celular mas a nora Ingrid me ajudou a fazer isso porque não sei lidar com a internet.

Pergunta 7 - Como soube que a ação poderia ser ajuizada pelo site? Já recebeu intimação (ões) por e-mail ou WhatsApp? Ou e-mail? Conseguiu atendê-la(s)?

AFRF - Minha sobrinha informou isso. Sim, por e-mail.

ISCRF - Pelo e-mail cadastrado no sistema da Justiça, para apresentar documentos. Conseguimos com ajuda da sobrinha da minha sogra.

Pergunta 8 - A sra. possui equipamentos eletrônicos que lhe possibilitem esse acesso à Justiça pela via eletrônica? Quais? Possuem computador, notebook, impressora, scanner em casa? Como é o acesso à Internet onde reside? 
AFRF - Só possuo mesmo o celular. Não temos outros aparelhos.

GRF - Não temos computador, notebook, impressora, temos o smartphone e o aplicativo de scanner. $\mathrm{O}$ acesso à internet é bom porque usamos o Wi-fi do meu primo que mora ao lado. Quando tem dinheiro, pode ser comprado o pacote de internet para o celular.

Pergunta 9 - Consegue utilizar por si e-mails e WhatsApp? Ou precisa da ajuda de alguém?

AFRF - Sozinha, uso melhor o Whatsapp, só para conversas.

GRF - Outras funções do WhatsApp e o e-mail, só com a nossa ajuda.

Pergunta 10 - A sra. teve ajuda de algum familiar ou amigo para ajuizar essa ação?

Teve alguma dificuldade em fazer esse ajuizamento? Como superou?

AFRF - Sim. Do meu filho e minha nora.

GRF - Não teve muita dificuldade porque contou com a nora e as orientações da minha prima, sozinha teria. Teve algumas dificuldades em relação à primeira intimação, não sabia para onde tinha que enviar o que foi pedido.

Pergunta 11 - Imagina que a maior parte das pessoas, nas mesmas condições financeiras e de idade em que a sra., teria condições de fazer esse ajuizamento pela via eletrônica sozinhas? Por quê?

AFRF - Acho que não porque, tirando por mim, eu não sei mexer em nada na internet. Se não fosse minha nora, eu estaria perdida.

Pergunta 12 - Como foi o passo a passo para fazer a atermação online? Precisou de teleatendimento para esclarecer dúvidas? Você escreveu o pedido inicial ou o sistema o gerou para você? Encaminhou o pedido para um órgão específico da Justiça?

ISCRF - Acessamos o site, fizemos o cadastro no sistema e depois acessamos o primeiro atendimento online, da LOAS, e fomos preenchendo os campos, expondo a situação da minha sogra sobre a necessidade de receber o benefício, anexando documento. Então, ao final, o sistema gerou um número para que pudéssemos acompanhar o andamento. Não precisamos do teleatendimento. Não escrevemos 0 texto do pedido como está, só informamos o que estava sendo pedido pelo sistema e também não dirigimos a um órgão específico, eu nem sabia para qual o órgão nem em que local ia ser julgado o processo.

Pergunta 13 - O serviço de atermação online atendeu às suas necessidades? Teria sugestões para aprimorá-lo? 
AFRF - Sim. Ajudou muito porque não tinha como esperar. Para melhorar, seria pessoalmente.

Pergunta 14 - A sra. considera que seria recomendável e até mesmo necessária uma iniciativa do Judiciário no sentido de capacitar o cidadão para o acesso à Justiça pelo processo eletrônico? Por quê?

AFRF - Sim. Porque como está sendo tudo eletrônico precisa sim.

GRF - E quem está sem advogado e não tem acesso a uma pessoa que sabe informar sobre como entrar com a ação fica muito mais difícil. ĺamos ter que pagar advogado sem ter como pagar. Se tivesse possibilidade de ter alguém para orientar também como dar andamento ao processo seria melhor para todos.

Pergunta 15 - Caso a Justiça promovesse um curso para ensinar o cidadão a utilizar o processo eletrônico a fim de exercer seu direito de acesso à Justiça, a sra. gostaria de participar? Teria condições de realizá-lo na modalidade online? Ou preferiria a modalidade presencial? Por quê?

AFRF - Sim, teria interesse em aprender. Poderia sim fazer, pelo celular porque não temos computador e, ainda assim, eu precisaria da ajuda de alguém. Preferiria a modalidade presencial porque ainda não sei mexer com a internet, eles que fizeram tudo por mim.

GRF e ISCRF - Sim. Sim, desde que pelo smartphone, porque não temos computador. Nós preferíamos presencial também porque tem maior oportunidade de fazer perguntas e esclarecer dúvidas. Tanto eu como a Ingrid não conseguiríamos sozinhos, dependemos de ajuda de outra pessoa que foi nossa prima para entrar com a ação embora a gente tenha conhecimento de como usar a internet.

Importa, por derradeiro, registrar que o primeiro contato com a Sra. Analicia de Fátima Ribeiro Freitas estabeleceu-se, em momento prévio à entrevista, por ocasião do cumprimento de mandado de verificação socioeconômica que viabilizasse a análise judicial quanto à concessão do benefício assistencial pleiteado, cumprimento esse que se deu igualmente pela via eletrônica, nos termos da Portaria n JFRJ-PGD2020/00023, de 03 de agosto de 2020 (SEÇÃO JUDICIÁRIA DO RIO DE JANEIRO, 2020b) e da Resolução no 317, de 30 de abril de 2020, do CNJ (CONSELHO NACIONAL DE JUSTIÇA, 2020a). A mencionada Resolução estabelece e regulamenta a realização de perícias médicas e socioeconômicas, por meio eletrônico, em processos judiciais que versem sobre benefícios previdenciários por 
incapacidade ou assistenciais, enquanto perdurarem os efeitos da crise ocasionada pela pandemia do novo Coronavírus. visando primados constitucionais da garantia do acesso à justiça e da dignidade da pessoa humana e dada a exigência de adoção de alternativas tecnológicas na condução dos processos para solucionar os litígios, de modo a preservar a incolumidade sanitária de todos os que atuam no sistema de justiça em razão do isolamento social para conter a transmissibilidade do Coronavírus.

Saliente-se ainda que, não obstante o desafio do peticionamento eletrônico via atermação online, em razão de dificuldades de acesso e uso das novas tecnologias, esse acesso do cidadão direto à Justiça tornou-se mais efetivo que o realizado em tempos de normalidade, em se tratando de Juizado Especial Federal Cível e Previdenciário de Itaperuna, onde proposta a ação da Sra. Analicia de Fátima Ribeiro Freitas. Isso porque, embora, ao peticionar, não fosse de seu conhecimento o órgão jurisdicional responsável por apreciar seu pedido, conseguiu, ainda que com ajuda de familiares, realizá-lo de forma direta, ainda que eletrônica, enquanto que, anteriormente à pandemia, esse peticionamento não se faria possível de forma direta, no âmbito do mencionado órgão jurisdicional, por não dispor ele de Núcleo de Primeiro Atendimento dos Juizados. Por esse motivo, os cidadãos que lá compareciam para peticionar de forma direta em Juízo, deduzindo verbalmente seu pedido, necessariamente, o fariam de forma indireta, por meio de advogados dativos nomeados pelo Juízo ou advogados de escritórios de prática jurídica de universidades conveniadas a quem encaminhados, tendo em vista que a localidade não dispõe de atendimento pela Defensoria Pública da União (RIBEIRO; SOUZA; AMARAL, 2018). 
Figura 1 - Print da videochamada via WhatsApp (entrevista)

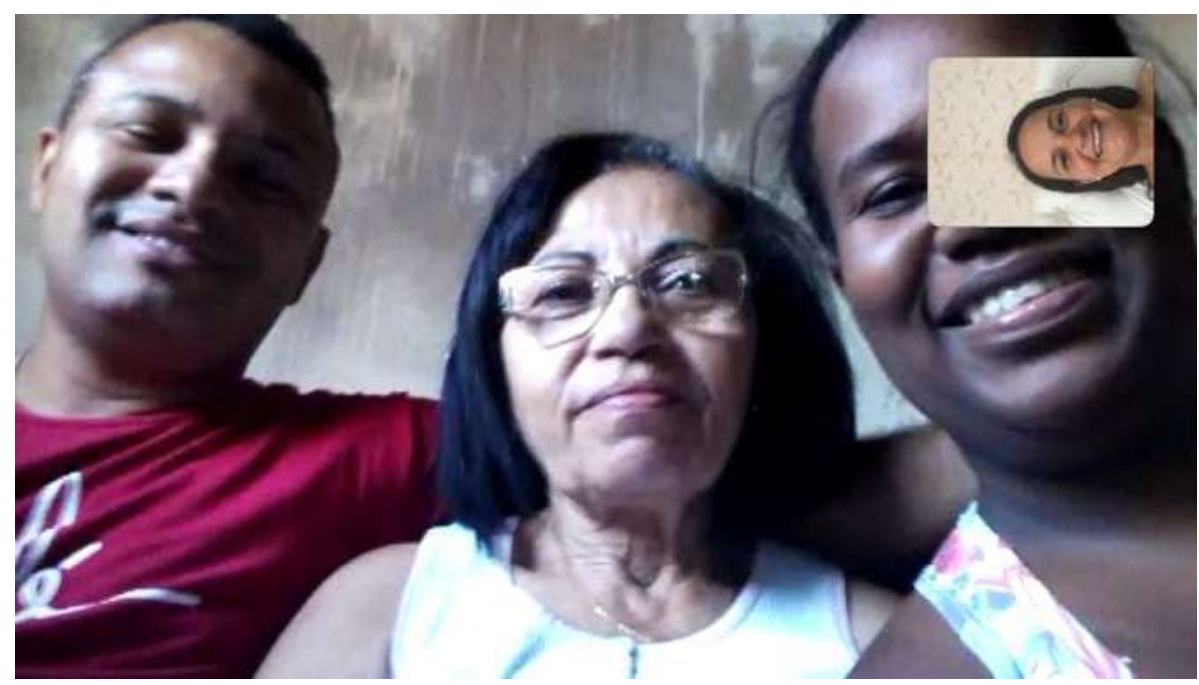

Fonte: Acervo pessoal da autora.

\section{CONSIDERAÇÕES FINAIS}

A efetividade do acesso à Justiça sempre foi questão tormentosa a desafiar o universo jurídico na busca de meios que a viabilizem no contexto de uma sociedade que se encontra em constante evolução. Não seria diferente nos dias atuais, em que se vivencia cada vez mais significativo desenvolvimento das tecnologias da informação e comunicação e a sua utilização em todos os campos de atuação humana, inclusive no Judiciário, meio em que traz consigo a expectativa de realização do ideal de promoção de uma Justiça que cumpra os anseios constitucionais de celeridade e eficiência.

Não obstante, não se pode olvidar que as conquistas tecnológicas no âmbito do Judiciário mais modernamente marcadas pela utilização dos sistemas de processamento eletrônico como via exclusiva de acesso à Justiça, podem representar significativo desafio aos cidadãos que não dispõem de acesso às tecnologias (equipamentos, internet) e/ou conhecimentos técnicos para sua utilização a fim de assegurar a efetividade ao seu direito humano de acesso à Justiça, de forma direta (por si, independentemente de advogado), nos amplos termos em que configurado nos tratados internacionais, na constituição e na legislação pátria.

Inegável que o Judiciário tem buscado, sobretudo durante a pandemia do Coronavírus (COVID-19), implementar meios que facilitem esse acesso direto do cidadão à Justiça, até mesmo pela inovadora possibilidade de atermação online, como 
aqui apresentada e exemplificada, o que, igualmente, não prescinde do acesso às novas tecnologias.

Assim sendo, à luz dos embasamentos teóricos delineados bem como da experiência da Sra. Analicia de Fátima Ribeiro Freitas, aqui retratada, percebe-se que ao mesmo tempo em que ela se mostra satisfeita por haver conseguido ajuizar sua ação mesmo diante do não funcionamento presencial dos órgãos jurisdicionais, acentua sua impossibilidade de fazê-lo por si, por não saber utilizar a internet para esse fim e afirma seu interesse em aprender a fazê-lo, preferencialmente, de forma presencial, realçando que até para realização do curso pela internet dependeria de auxílio. Esse depoimento revela sua limitação no tocante à utilização da via eletrônica para assegurar o seu acesso direto à Justiça e ilustra a realidade de muitos brasileiros que, como ela, podem ter a mesma limitação, quer em razão de condições socioeconômicas, educacionais e/ou etárias, não sendo nenhuma delas, por si sós, fator determinante para a inaptidão ao peticionamento eletrônico, já que também se consideraram também assim seu filho e sua nora, que embora possuam a mesma formação (ensino médio), são jovens e se utilizam das tecnologias para outras finalidades. Eles mesmos, por sua vez, também afirmam possuir interesse em aprender, de preferência, presencialmente, como realizar o acesso à Justiça pela via eletrônica, não somente para o peticionamento em si mas para os demais atos do processo pois até mesmo para o simples preenchimento dos dados para a realização da atermação online necessitaram de ajuda de terceiros.

Assim, conclui-se que a atermação online, embora constitua um desafio para muitos cidadãos, em razão de não prescindir da utilização das tecnologias, tem contribuído para efetividade do acesso do cidadão à Justiça, nos tempos de pandemia, à medida que lhes permite deduzirem em Juízo seu pedido não oral, mas escrito, ainda que eletronicamente e eventualmente com ajuda de terceiros, embora não de forma plena. Isso porque essa medida não afasta, antes conclama a adoção, por parte do Judiciário, das medidas sugeridas por Ribeiro e Souza, que efetivem os comandos legais previstos na legislação pátria relativos tanto à disponibilização de equipamento ao cidadão para o acesso à Justiça quanto à inclusão digital do cidadão no âmbito do Judiciário. Sem a adoção de tais medidas, não somente a atermação online, como as demais estratégias de facilitação do acesso à Justiça, pela via eletrônica, adotadas pelo Judiciário, mormente durante a pandemia, embora louváveis, restarão inaptas a 
viabilizar, no contexto de uma Justiça eletrônica, o efetivo acesso direto à Justiça desse cidadão nos amplos termos em que preconizado pelas normas internacionais e nacionais vigentes.

\section{REFERÊNCIAS}

BARCELLOS, Ana Paula de. A eficácia jurídica dos princípios constitucionais: o princípio da dignidade da humana. 2. ed. amp. rev. atual. Rio de Janeiro: Renovar, 2008.

BARCELLOS, Ana Paula de. Curso de Direito Constitucional. Rio de Janeiro: Forense, 2018.

BRASIL. [Constituição (1988)]. Constituição da República Federativa do Brasil de 1988. Brasília, DF: Presidência da República, [2020]. Disponível em:

http://www.planalto.gov.br/ccivil_03/constituicao/constituicao.htm. Acesso em: 26 out. 2020.

BRASIL. Decreto no 592, de 06 de julho de 1992. Promulga o Pacto Internacional sobre Direitos Civis e Políticos. Brasília, DF: Presidência da República, 1992a. Disponível em: http://www.planalto.gov.br/ccivil_03/decreto/1990-1994/d0592.htm. Acesso em: 16 out. 2018.

BRASIL. Decreto no 678, de 06 de novembro de 1992. Promulga a Convenção Americana sobre Direitos Humanos (Pacto de São José da Costa Rica), de 22 de novembro de 1969. Brasília, DF: Presidência da República, 1992b. Disponível em: http://www.planalto.gov.br/ccivil_03/decreto/d0678.htm\#: :text=DECRETO\%20No\%2 0678\%2C\%20DE,que\%20lhe\%20confere\%200\%20art. Acesso em: 08 out. 2018.

BRASIL. Lei no 9.099, de 26 de setembro de 1995. Dispõe sobre os Juizados Especiais Cíveis e Criminais. Brasília, DF: Presidência da República, 1995. Disponível em: http://www.planalto.gov.br/ccivil_03/leis/19099.htm. Acesso em: 01 jun. 2020.

BRASIL. Lei no 11.419, de 19 de dezembro de 2006. Dispõe sobre a informatização do processo judicial [...]. Brasília, DF: Presidência da República: 2006. Disponível em: http://www.planalto.gov.br/ccivil_03/_ato2004-2006/2006/lei//11419.htm. Acesso em: 01 jun. 2020.

BRASIL. Lei no 12.965, de 23 de abril de 2014. Estabelece princípios, garantias, direitos e deveres para o uso da Internet no Brasil. Brasília, DF: Presidência da República, [2018]. Disponível em: http://www.planalto.gov.br/ccivil_03/_ato20112014/2014/lei//12965.htm\#: :text=1\%C2\%BA\%20Esta\%20Lei\%20estabelece\%20pri nc\%C3\%ADpios,Munic\%C3\%ADpios\%20em\%20rela\%C3\%A7\%C3\%A30\%20\%C3\% A0\%20mat\%C3\%A9ria.\&text=Vl\%20\%2D\%20a\%20finalidade\%20social\%20da\%20r ede. Acesso em: 02 jun. 2020. 
CAPPELLETTI, Mauro; GARTH, Bryant. Acesso à Justiça. Porto Alegre: Sergio Antonio Fabris Editor, 1988.

CENTRO REGIONAL DE ESTUDOS PARA O DESENVOLVIMENTO DA SOCIEDADE DA INFORMAÇÃO (Brasil). Três em cada quatro brasileiros já utilizam a Internet, aponta pesquisa TIC Domicílios 2019. Disponível em: https://cetic.br/pt/noticia/tres-em-cada-quatro-brasileiros-ja-utilizam-a-internetaponta-pesquisa-tic-domicilios-2019/. Acesso em: 10 ago. 2020.

CONSELHO NACIONAL DE JUSTIÇA (Brasil). Resolução no 313, de 19 de março de 2020. Brasília, DF: CNJ, 2020b. Disponível em:

https://www.conjur.com.br/dl/resolucao-313-19-marco-2020-cnj-cnj.pdf. Acesso em: 30 jul. 2020.

CONSELHO NACIONAL DE JUSTIÇA (Brasil). Resolução no 317, de 30 de abril de 2020. Brasília, DF: CNJ, 2020a. Disponível em:

https://atos.cnj.jus.br/files/original161656202005085eb585f8b31d5.pdf. Acesso em: 19 set. 2020.

MARINHO, Elton. Novas Tecnologias da Informação e Comunicação (NTICs). Goiatuba, 2017. Disponível em:

http://www.ebah.com.br/con0tent/ABAAABAiMAB/novas-tecnologias-informacaocomunicacao-ntics. Acesso em: 30 mai. 2018.

ONU. Declaração Universal dos Direitos Humanos (1948). Rio de Janeiro: UNIC, 2009. Disponível em: https://nacoesunidas.org/wp-

content/uploads/2018/10/DUDH.pdf. Acesso em: 10 ago. 2020.

RAMOS, André de Carvalho. Curso de Direitos Humanos. São Paulo: Saraiva, 2020.

RIBEIRO, Leila Maria Tinoco Boechat; FRIAS, Mônica Lúcia do Nascimento; SOUZA, Carlos Henrique Medeiros de. Juizados Especiais e Processo Eletrônico: Vaivém das Ondas Cappellettianas e Retrocesso Social? Revista Lex Magister de Direito Civil e Processual Civil, Porto Alegre, v. 86, p. 64-81, set./out. 2018.

RIBEIRO, Leila Maria Tinoco Boechat; SOUZA, Carlos Henrique Medeiros De. Processo eletrônico e (não) comunicação dos atos processuais ao cidadão: violação ao contraditório e ampla defesa?. In: CONINTER, 8., 2019, Maceió. Anais [...]. Maceió: Unit, 2019. Disponível em: https//www.even3.com.br/anais/coninter2019. Acesso em: 28 jul. 2020.

RIBEIRO, Leila Maria Tinoco Boechat; SOUZA, Carlos Henrique Medeiros de; AMARAL, Shirlena Campos de Souza. Acessibilidade Social: um novo conceito como fator de inclusão no acesso à Justiça via processo eletrônico, à luz do princípio da isonomia material. Revista Lex Magister de Direito Civil e Processual Civil, Porto Alegre, v. 87, p. 84-105, Nov-Dez, 2018. 
SEÇÃO JUDICIÁRIA DO RIO DE JANEIRO. Justiça Federal não parou: estamos trabalhando remotamente: como ser atendido durante a pandemia? Disponível em: https://www.jfrj.jus.br/noticia/justica-federal-nao-parou-estamos-trabalhandoremotamente-como-ser-atendido-durante-pandemia. Rio de Janeiro: SJRJ, 2020a. Acesso em: 21 jul. 2020.

SEÇÃO JUDICIÁRIA DO RIO DE JANEIRO. Portaria no JFRJ-PGD-2020/00023, de 3 de agosto de 2020. Rio de Janeiro: SJRJ, 2020b. Disponível em: https://www.jfr.jus.br/sites/default/files/SEASI/portaria_jfrj-pgd-202000023.pdf. Acesso em: 19 set. 2020.

SEIXAS, Bernardo Silva de; SOUZA, Roberta Kelly Silva. Evolução histórica do acesso à justiça nas constituições brasileiras. Direito e Democracia, Canoas, v.14, n.1, p. 68-85, jan./jun. 2013.

SOUZA, Carlos Henrique Medeiros de. Comunicação, educação e novas tecnologias. Campos dos Goytacazes, RJ: Editora FAFIC, 2003. 